\title{
Новые электронные состояния на интерфейсе p-GaN(Cs,O)-вакуум при больших (Cs,O)-покрытиях
}

\author{
Г.Э. Шайблер ${ }^{1,2)}$, В.В. Бакин ${ }^{1)}$, С.Н. Косолобов ${ }^{1)}$, С.А. Рожков ${ }^{1,2)}$, А.С. Терехов ${ }^{1)}$ \\ ${ }^{1}$ Институт физики полупроводников им. А.В. Ржанова СО РАН, \\ Новосибирск, 630090, пр. Ак. Лаврентьева, 13 \\ ${ }^{2}$ Новосибирский Государственный Университет, Новосибирск, 630090, Пирогова, 2 \\ тел:+7 (383) 330-98-74, факс:+7 (383) 333-27-71, эл. nочта: scheibl@ isp.nsc.ru
}

DOI 10.34077/RCSP2019-132

Фотокатоды с эффективным отрицательным электронным сродством (ОЭС), созданные на основе эпитаксиальных p-GaN - слоёв с субмонослойными $(\mathrm{Cs}, \mathrm{O})$-покрытиями, обладают высокой квантовой эффективностью в УФ - области спектра. Фотоприёмники с такими фотокатодами широко используются в системах дистанционного контроля потерь электроэнергии на высоковольтных установках и линиях электропередачи, а также в важных системах специального назначения. Несмотря на существенные успехи в разработках $\mathrm{p}-\mathrm{GaN}(\mathrm{Cs}, \mathrm{O})$-фотокатодов для УФфотоприёмников, связи неупорядоченной атомной структуры интерфейсов $\mathrm{p}-\mathrm{GaN}(\mathrm{Cs}, \mathrm{O})$-вакуум с их фото - и термо - эмиссионными свойствами изучены недостаточно. Существующие методики формирования оптимального $(\mathrm{Cs}, \mathrm{O})$ - покрытия $\left(\theta_{\text {оп }}\right)$, обеспечивающего максимальную вероятность выхода фотоэлектронов из $\mathrm{p}-\mathrm{GaN}(\mathrm{Cs}, \mathrm{O})$ - фотокатода в вакуум $\left(\mathrm{P}_{\mathrm{e}}\right)$, найдены эмпирически и не гарантируют достижения её физически - предельного значения. Пытаясь глубже понять закономерности формирования атомной структуры и энергетической диаграммы ОЭС - интерфейса $\mathrm{p}-\mathrm{GaN}(\mathrm{Cs}, \mathrm{O})$ - фотокатода, мы впервые изучили в данной работе спонтанные изменения $\mathrm{P}_{\mathrm{e}}(\mathrm{t})$ и энергетических распределений фотоэлектронов $\left(\mathrm{n}_{\mathrm{e}}\left(\varepsilon_{\mathrm{lon}}, \mathrm{t}\right)\right)$, эмитированных из фотокатода с $(\mathrm{Cs}, \mathrm{O})-$

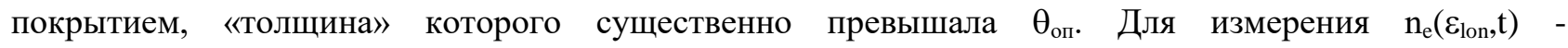
распределений мы установили в камеру формирования $(\mathrm{Cs}, \mathrm{O})$ - покрытия простейший электронный спектрометр с однородным тормозящим электрическим полем [1]. Эксперименты проводились в экстремально - высоком вакууме, в котором изменения $\mathrm{P}_{\mathrm{e}}(\mathrm{t})$ в результате адсорбции остаточных газов были невелики [1]. На поверхность p-GaN было нанесено (Cs,O) - покрытие в три раза превышающее

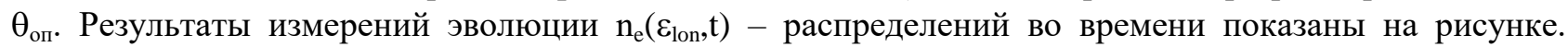
Время $\mathrm{t}$ на рисунке соответствуют интервалу времени между моментом завершения нанесения $(\mathrm{Cs}, \mathrm{O})$

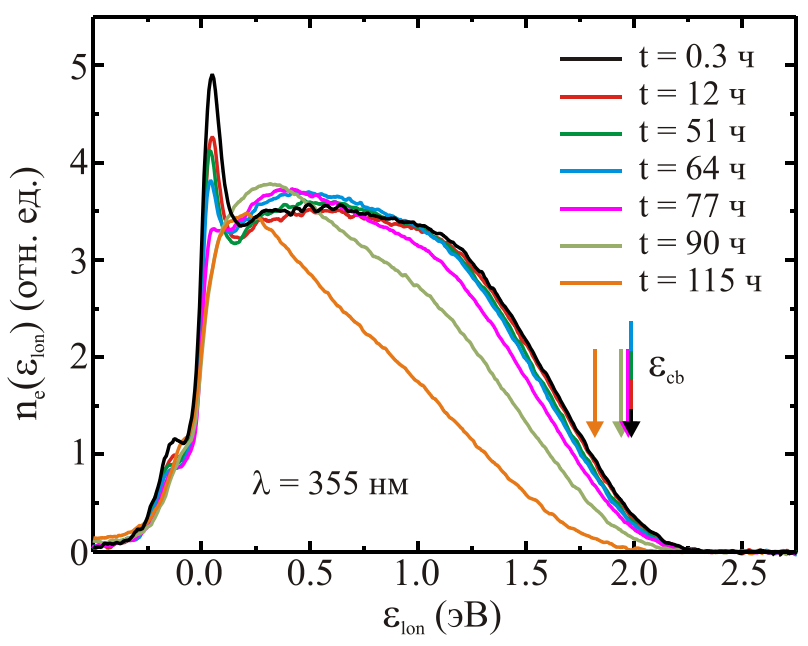
- покрытия и моментом измерения соответствующего $\mathrm{n}_{\mathrm{e}}\left(\varepsilon_{\mathrm{lon}}\right)-$ распределения. Энергетические положения дна зоны проводимости $\left(\varepsilon_{\mathrm{cb}}\right)$ в объёме $\mathrm{p}-\mathrm{GaN}$-слоя обозначены на рисунке вертикальными стрелками соответствующего цвета. Необычной особенностью $\mathrm{n}_{\mathrm{e}}\left(\varepsilon_{\mathrm{lon}}\right)$ - распределений на рисунке является узкий пик, расположенный при малых $\varepsilon_{\text {lon. }}$ Из рисунка следует, что амплитуда пика снижалась в течение первых $\sim 60$ часов, в то время как изменения энергетического положения его максимума и положения $\varepsilon_{\mathrm{cb}}$ в течение этого времени оказались близки к погрешности измерений. Отметим, что форма высокоэнергетического крыла $\mathrm{n}_{\mathrm{e}}\left(\varepsilon_{\text {lon }}\right)$ распределения в течение первых $\sim 50$ часов фактически не изменялась. Дальнейшее увеличение $\mathrm{t}$ сопровождалось смещением $\varepsilon_{\mathrm{cb}}$ в область меньших $\varepsilon_{\text {lon }}$ и выраженным снижением амплитуды высокоэнергетического крыла $\mathrm{n}_{\mathrm{e}}\left(\varepsilon_{\text {lon }}\right)$ распределения из - увеличения вероятности рассеяния и рекомбинации выходящих в вакуум фотоэлектронов. Мы полагаем, что возникновение пика в $\mathrm{n}_{\mathrm{e}}\left(\varepsilon_{\text {lon }}\right)$-распределениях связано с резонансным электронным состоянием на интерфейсе $\mathrm{p}-\mathrm{GaN}(\mathrm{Cs}, \mathrm{O})$-вакуум, увеличивающим вероятность выхода электронов. Работа выполнена при поддержке РФФИ (проект 19-02-00517).

\section{Литература}

[1] В.В.Бакин и др. // Письма в ЖЭТФ. 2018. Т.108, вып.3. С.180-184. 